\title{
Study reveals risk factors for teen suicide
}

Tew findings on teen suicide and sexual 1 orientation have illuminated an array of risk factors linked to suicide attempts and suicidal thoughts reported by young people.

In the first study using nationally representative data, Stephen Russell of UC Davis and Kara Joyner of Cornell University found that youth with same-sex sexual orientations were twice as likely as their peers to attempt suicide and have suicidal thoughts. The study was published in the American Journal of Public Health in August 2001.

The rising rate of teenage suicide has attracted nationwide concern. Between 1980 and 1997, the rate of suicide increased $11 \%$ for 15 - to 19-yearolds; suicides among adolescents and young adults nearly tripled between 1952 and 1995.

The findings, coupled with a 5-year, $\$ 300,000$ research grant from the William T. Grant Foundation, will help California's $4-\mathrm{H}$ youth program develop innovative prevention programs targeting at-risk youth. Russell is a $4-\mathrm{H}$ youth development specialist with a research emphasis in adolescent development, youth and families at risk in the UC Division of Agriculture and Natural Resources (DANR) (see California Agriculture 54[1]:48-54).

"Cooperative Extension nationally is committed to working with at-risk youth populations. Our programs have to be relevant to kids, and issues important to teens include sexuality. We cannot ignore this important component of kids' lives," Russell says. "This study is a first step to identify what kids need, whether it be help coping with substance abuse, sexuality, depression or victimization."

The scientists analyzed 1995 data collected by the National Longitudinal Study of Adolescent Health (Add Health), a long-term, federally funded survey, which amassed information on multiple aspects of U.S. adolescent health and behavior from 6,254 girls and 5,686 boys between 12 and 18 years old.

The data was collected from a stratified, random sample including youth from 145 middle, junior high and high schools. The sample repre- sented 22 million U.S. teenagers.

Of heterosexual youth surveyed, $12 \%$ thought of suicide and $4 \%$ attempted it; among gay youth, $23 \%$ had suicidal thoughts and about $8 \%$ made attempts. Russell and Joyner defined gay youth as those who reported having a romantic attraction to, or relationship with, a member of the same sex.

The finding of elevated suicide risk among gay teens can be partly explained by risk factors that could affect any adolescent: depression, hopelessness, substance abuse, the recent suicide or attempted suicide of a family member or close friend, or experiences of victimization. However, the analysis showed that gay boys and girls reported significantly more of many of these factors.

Russell is a member of the 4-H Center for Youth Development, established in 1994 by DANR and UC Davis to provide statewide leadership in research and evaluation relating to youth; one of its emphases is developing new 4-H program components. The Center is completing research under a 5-year federal grant for the CYFAR (Children, Youth and Families At Risk) initiative, to expand 4-H outreach programs to at-risk youth.

"This study provides a foundation for program development. The first step is to learn about your audience and then determine the most useful ways to serve them," says Marc Braverman, another specialist at the 4-H Center for Youth Development.

Russell notes that the overwhelming majority of gay youth, $84.6 \%$ of males and $71.7 \%$ of females, reported no suicide thoughts or attempts at all. "Nevertheless, a significant number are at risk," he said. "They deserve intervention and prevention attention." 